\title{
Sign Construction Based on Heightened Tactile Perception by Persons with Congenital Deafblindness
}

\author{
Gøran Andreas Gregor Caspian Forsgren, \\ Marlene Daelman \& Paul Hart
}

\begin{abstract}
Low readability is a main concern regarding communication with persons with congenital deafblindness (Nafstad \& Rødbroe, 2015). This is because most of the expressions come from the bodily-tactile modality and are often based on tactile iconicity. It is difficult for a seeing and hearing partner to understand these expressions from the perspective of cultural language.

The goal of this qualitative study is to show the emergence of sign constructions based on heightened tactile perception (Borchgrevink, 2002; Nicholas, 2004). Two videos, each showing one of two participants with congenital deafblindness, were subjected to qualitative micro-analysis. A key focus of this research concerns the combination of exploration and cognitive processing indicated by self-addressed expressions, and how this combination contributes to sign constructions. The linguistic quality of these sign constructions is further examined by detailing handshape, movement and location according to the work by Stokoe, 1960 and Bellugi \& Klima, 2001. The results provide support for the proposition of a new sign category based on heightened tactile perception.
\end{abstract}

\section{Keywords}

Sign construction, Tactile, Exploration, Cognitive Processing, Handshapes, Readability. 


\section{Introduction}

The Communication with persons who are congenitally deafblind is challenging because of the creative and idiosyncratic nature of their expressions leading to low readability (Nafstad \& Rødbroe, 2015). The readability issue may be further complicated by lack of proficiency in communication in the seeing and hearing partners regarding sign language and tactile communication methods. Lack of proficiency can mean that partners see neither the expression itself, nor the linguistic aspects in the expression. Otherwise competent communication partners who lack experience with these methods can become uncertain when faced with the child's developing creative ability to construct linguistic expressions; this uncertainty can be a negative factor in the teaching/caregiving environment (Nafstad \& Rødbroe, 2015).

Regarding readability the analysis in this study will show that the non-conventional sign constructions emerging are not seen, understood or answered as signs by the sighted and hearing conversational partner when they occur. The non-conventional sign function is, in other words, not socially constructed in the interaction with the partner. By consequence the lexical meaning is not negotiated.

\section{Sign construction}

It is important to distinguish between the linguistic and the cultural aspect (i.e. negotiated lexical meaning) regarding signs. The constructions mapped out in the analysis have all the linguistic elements of a sign: handshape, movement and location (Stokoe, 2005; Bellugi \& Klima, 2001); thus, they are labeled as such. In addition, the sign construction also takes on the form of depicting constructions (Cormier et al., 2012), where the handshape identifies the class of referent (e.g. an upright flat surface with some characteristics, picture $3 \mathrm{~A}$ and B) and thus displays grammatical elements.

Further, when looking at the sign constructions considering the theory of 'gesture verbs' (Erlenkamp, 2009), the linguistic elements are clearly present. It is suggested that handshape, the orientation of the hand, location in space and/or movement are to be treated as different morphemes and suggests further that, "the movement is the verb stem or root since the movement indicates more than the other parts the semantic description of the verb's action" (Supalla, 1982, cited in Erlenkamp, 2009). Further Erlenkamp (2009) refers to McDonald (1983) who regards the handshape as the core morpheme of this type of sign. Despite disagreement in the literature regarding core morphemes, both views support the notion that the sign constructions found in this research take on linguistic form. Hence these forms should be treated linguistically, even though no negotiation has taken place, neither regarding form, function nor meaning. If the linguistic forms are to be stabilized the sign constructions 
must undergo a negotiation process so that they are transferred into the realm of sign constructions with shared meaning.

All the non-conventional sign constructions found in this study contain movement in the form of verb-like aspects. For example, the "pacifier in hands" sign construction with movement (discussed more fully later) will show the verb-aspect of how the pacifier is held and moved towards the mouth. Accordingly, these constructions cannot alone be classified as nouns, but rather as nouns with an integrated verb-aspect. Both the sign constructions and the movements have an iconic form, showing the creative cognitive process that occurs in sign constructions: iconicity and metonymy. Cognitive iconicity is "defined not as a relation between the form of a sign and real-world referent, but as a relation between two conceptual spaces" (Wilcox et al., 2003, p. 142). In analyzing American Sign Language, Liddell (2003) found that these two spaces are real space (a grounded space) and event space (a nongrounded space), saying that a space is grounded when "its elements are conceptualized as existing in the immediate environment" (2003, p. 83).

Regarding metonymy, Radden and Kövecses (1999) (cited in Erlenkamp 2009) state that, "metonymy is a cognitive process in which one conceptual entity, the vehicle, provides mental access to another conceptual entity, the target, within the same cognitive model" (1999, p. 21). Wilcox et al. (2003, p. 139) describe basic metonymies as "action for instrument" and "prototypical action for activity". Further, they claim that, "metonymy.... is iconically depicted in the articulated form of the signs..." (p. 141).

Both Wilcox et al. (2003) and Radden and Kövecses (1999) refer to these conceptual spaces/entities that are parts of the real space blend (Liddell, 2000). In the sign constructions found in this study, real space blend shows itself by the signers using constructions which are held in their mental space, and transferring them into the real space, the conversational space. As an example, the analysis of the 'WALL' sign construction based on HTP (picture $3 \mathrm{~A}$ and B) (also to be discussed more fully later), which is the boy's cognitively perceived image of the wall, is articulated in the conversational frame, showing the cognitive construction and its interaction between linguistic elements and mental spaces (Souriau, 2015; Liddell, 2003; Fauconnier, 1997; Fauconnier and Turner, 2002).

As the analysis will show, the signs constructed are highly iconic (e.g. "pacifier in mouth" sign construction). This observation leads us to the Analogue-Building Model of Linguistic Iconicity (Taub, 2001) which focuses on image selection, schematization and encoding. The image selection comes from what is being explored and, during this process; the chosen tactile image is modified or schematized, so that it is possible to make a linguistic representation of it using a single or dual handshape. In an interview with the boy from the video 'THE WALL', he explains that exploration and cognition take place at the same time, and that this process leads to the formation of an image in his thoughts that is the basis for forming an image of the sign he wants to represent. 
During the process of schematizing, the forms or functions characteristic of the object are chosen for the sign representation. Here it is evident that the schematization process coincides with the tactile perceptual process, which focuses on the perceived features of the object. In the interview the boy discloses that for him it is primarily the form that occupies his cognitive space, not the function of the object. Although when he is signing, he also represents the function of the object. This is seen in the interview, where an experiment was conducted, and the boy was able to explore an object, a pacifier, not being told what it was. After exploring the pacifier, he was asked if he could represent the object with a sign. The first sign he made was an " $A$ " handshape with his thumb moving, this being an exact match for the manner in which he had held the pacifier and touched the tip with his thumb. The second sign he joins hands held together, as if he is holding the object, followed by a small "o" handshape with his right hand (representing a mouth) and a "pointing" handshape with his left hand (representing the pacifier), putting the "pointing" index finger into the "o". This sign construction shows the function of the pacifier: an object to hold on to and an object that can be inserted into the mouth.

The encoding consists in choosing a physical form to represent each piece, and the signer ensures that this substitution process preserves the overall structure of the original image obtained during exploration and cognitive processing. The encoding process here coincides with the tactile cognitive processing; in the tactile working memory, the image of what has been explored lingers and is now capable of being expressed as a sign construction (i.e. tactile language).

In addition, this study focuses on how exploration (Nafstad \& Rødbroe, 2015) and cognitive processing (i.e. how the tactile perceived information is cognitively processed) (cf. e.g. Nelson, 1996; Radden \& Kövecses, 1999; Taub, 2001; Nicholas, 2010) are an integral part of the process of sign construction. The cognitive categorization processes that are involved in sign construction (Nelson, 1996; Johnson, 1987) are considered, as well as how mental directedness (Nafstad, 2016, personal communication) plays an important role during processes of sign construction.

\section{Heightened tactile perception}

Heightened tactile perception is a concept derived by the author based on studies showing that within the deafblind population, the visual and auditory cortex take over processing of tactile information when seeing and/or hearing is impaired (Borchgrevink, 2002; Nicholas, 2004) thus leading to heightened sensitivity to tactile stimulation. It is argued here that this heightened sensitivity is the main source of perceptual information in persons with $\mathrm{CDB}$, even those who retain residual hearing and/or vision. The author of this article emphasizes the distinction between the linguistic and the cultural (i.e. the negotiated lexical meaning) aspects of signs. The focus in this article is solely on the linguistic elements that 
occur before the sign constructions are understood, met and negotiated. To obtain shared understanding of the sign constructions produced they must be negotiated so that the lexical meaning is the same for the person with CDB and the seeing/hearing partner. However, even when not negotiated, the sign construction is of linguistic quality and the author focuses on the origin of the sign construction and how heightened tactile perception plays an important role in the construction itself.

\section{Language as action}

Gallagher and Zahavi (2008, p. 153) refer to Heidegger in saying that, "the world, rather than being simply a complex unity of objects characterized by substantiality, materiality, and extension, is in fact a network of meaning. More precisely the world we live in, and the world as we perceive it, is a world saturated by practical references of use". When we look at the way persons with CDB live in the world, this gives meaning regarding usage of these practical references to create language. Ergo establishing a "first language" to give meaning to their experiences, coming both from bodily-tactile impressions of objects and activities, obtained from their surroundings. If one looks at the use of language as action, Gallagher and Zahavi (2008, p. 154) state that, "action is always action in a particular environment that is both physical and social, and such factors shape our intentions". Whereas Linell (2009, p. 113) states, "action is, almost per definition, intentional and conscious". Thus, the activity of creating pieces of language has intentionality when it comes to communicating in social settings, whether it is to merely to participate in social interaction, to ask or answer questions, to share one's thoughts or simply try to understand the world. In cases of severely limited vocabulary, the language-creating mind can be seen as making the most of what is there, compensating for the limited access to the external world.

\section{Methods}

\section{Design}

This study is a qualitative case study (Marková, 2003) based on the microanalysis (described below) of expressions (i.e. sign constructions) arising from case subjects' exploration and cognitive processing of object. The central objective was to show how exploration (Nafstad \& Rødbroe, 2015) of the form and function of objects by persons with CDB takes place, and manifests into construction of new signs. Marková (2003) describes the methodology in terms of 'idiographic' procedures, focusing on making generalizations from facts to theory, involving in-depth study of single cases to produce generalized knowledge, "although of a different kind than the nomothetic approach". The nomothetic approach is based on induction through the aggregation of data from individual cases, and computing 
probabilities based on statistical averages which allow data to be generalized to populations. By contrast, the idiographic approach is not used to generalize from the case to the population but rather from the facts to the theory.

Corbin and Strauss (2015) define microanalysis as "detailed coding for and around a concept, looking for properties and dimensions". Based on the microanalysis, a qualitative analysis involving "thought processes that go on when interpreting data and assigning concepts to stand for meaning" (p. 57) has been performed. The interpretation process is of a complex nature and it is important for all interpretations to be carefully assessed, described and supported. This is due to the low readability in the expressions themselves and to the fact that the expressions come from a bodily-tactile modality, not resembling cultural languages.

Two videos were selected because of their richness both in terms of the exploration demonstrated by the subjects and the sign constructions arising from this exploration. When doing video analysis there is a wide range of computer programs available. The author has chosen to use the program NVivo for Mac, version 11. This program is well suited for analyzing communication and sign constructions due to the possibility of making nodes and marking out the sequences as it is being analyzed. Predefined nodes, made by the author, such as exploration, cognitive processing and sign constructions, based on the researcher's sign language knowledge as an interpreter were used as a basis to determine the final nodes. Bryman (2012, p. 596) has the following definition; "A node is a collection of references about a specific theme, place, person or another area of interest". All nodes connected to mapping out sign constructions are based on sign language theory concerning the linguistic elements of a sign: handshape, movement and location (Stokoe, 1960; Bellugi \& Klima 2001).

To further establish reliability and validity, a semi-structured interview with the boy from the video 'THE WALL' was conducted and analyzed regarding the content of his answers. The interview focused on the boy's understanding of language and on his views about what had taken place in the video itself.

With regards to the reliability of the video analysis, an expert in the field of sign language linguistics, Vibeke Bø, from Oslo and Akershus University College of Applied Sciences was contacted. The videos were re-analyzed together with this expert, who came to the same conclusions as the author when looking at the content of the videos. The expert, however, picked up several non-manual features in the videos that the author had not considered. This due to the author only looking at the signing elements made by the hands, excluding all the non-manual features connected to the signs.

\section{Participants}

The empirical data is based on examples from two videos showing two persons with CDB engaged in language-producing activities. The examples have been selected for their richness regarding the subjects' creative use of sign construction. At the time of the video recordings, 
the participants were 6 months and 14 years of age respectively, both are blind with residual hearing, and the diagnostic basis for the congenital deafblindness in both cases is unknown.

Participant 1, Boy 14 years of age is born blind (microphthalamia) with impaired hearing function of unknown cause and character. There is also a tentative diagnosis of developmental aphasia. The reason for the congenital deafblindness is unknown. In his upbringing there have been uncertainties about how he has used his hearing, but today, at age 19, he seems to function as blind with normal hearing in some situations, whereas in other situations his deafblindness is more prominent. His initial form of expressive communication was a small vocabulary of negotiated idiosyncratic tactile signs. The partners used spoken language supported by signs in the tactile modality. His form of communication became progressively more complex through the use of the computer assisted software called Sarepta begun when the boy was 12 years old. The use of this software is likely to have supported both his understanding of spoken language and his ability to match the letters in the two-hand manual alphabet to sounds. Today his preferred method of communication is using the two-hand manual, spelling out everything he wishes to say, using the correct Norwegian grammar. It is hypothesized that the combined use of tactile communication and Sarepta has helped him to communicate expressively and better understand and make sense of the spoken language.

Participant 2, Child 6 months of age is born blind and deaf (no reaction to sound at $80 \mathrm{Db}$ ). He initially used hearing aids with the aim of supporting and stimulating the auditory nerves and was later successfully cochlear implanted (at 1 year of age). From observations we presume that he now has access to spoken language through hearing. The reason for the congenital deafblindness is still unknown, but under assessment. There is a focus on using signs in the tactile modality in communication with him, accompanied by speech. Parents and network are receiving counselling on both communications in the tactile modality and on speech development. Today the child mainly produces signs and a few recognizable words.

\section{Data collection}

The first video, 'THE WALL', was filmed during a winter camp in Sømådalen, Norway as a part of the project "Bua mi" (My little hut) led by Kari Schjøll Brede at Eikholt National Resource Center for Persons with Deafblindness, which was focused on language development and language acquisition for persons with CDB through meaningful activities. The video was taken ${ }^{1}$ as part of a parallel pilot study, "Congenital Deafblind Persons' Way into Language" conducted by Statped Southeast Norway. The goal of the pilot study was to increase knowledge about persons with congenital deafblindness' natural linguistic expressions in order to increase readability and, through this, improve the dialogical situation.

\footnotetext{
${ }^{1}$ The video was made by Hege Kristine Høgmo, senior advisor at Statped Southeast, Norway.
} 
The second video, 'THE PACIFIER', was filmed and submitted by the child's parents as part of ongoing supervision by the author and other colleagues at Statped Southeast regarding language development.

Permission for the use of the videos in the study has been obtained through informed, written consent from both case persons' parents.

\section{'THE WALL'}

The first sequence selected for microanalysis has a duration of 01:35 minutes is taken from the original video (duration 12:10 minutes) and contains the sequence in which the 'WALL' sign construction based on heightened tactile perception can be seen.

The chosen sequence will be analyzed with a focus on exploration, cognitive processing and sign construction. In addition to examining handshape, movement and location, the way the case person (the boy) positions himself also provides a basis for analysis of the expressions with regard to whether they are seen as direct communication or as expressions of cognitive processing. Expressions made by the boy while in direct tactile communication with his teacher are coded as sign constructions and treated as related to communication of his comprehension of what has been explored or how he has read his teacher's sign. When the boy is in active exploration and not in physical contact or direct tactile communication with his teacher, the instances in which he withdraws his hand(s) from the activity are coded as though he is in a thinking position, i.e. as self-addressed (Nafstad, 2016, personal communication) and cognitively processing what he is exploring.

\section{'THE PACIFIER'}

The original video with duration of 40.9 seconds will be used in its entirety for the microanalysis. The sequence will be divided into four parts, the first two when the child has the pacifier in his mouth and the second two when it is out of his mouth. The reason for this distinction is that different qualities can be distinguished in the expressions made when the pacifier is in or out of the child's mouth in relation to their varying intensity. The segment analysis will focus on exploration, cognitive processing and sign production.

\section{Results}

\section{Results Analysis of the 'THE WALL'}

The teacher invites the boy to take part in physical exploration of the wall without her naming the object of exploration. The goal is to get him to use his hands to find out what the object is. In this way, she is creating a game such as "name the object", invoking his curiosity and his natural way of seeing objects in the world. To begin the exploration, the boy aligns his 
attentional focus towards the wall through his teacher by reading her arm movement, thus exploring the wall through her when she makes a sweeping motion down the wall.

Using his right index finger, he reads the way she is exploring the wall, at the same time as the rest of his fingers are in contact with the same wall. Here he obtains additional information through her hand, her palm is outstretched, pressed flat against the wall, and he can feel the carpals tensed on the back of her hand. This gives him the information that she is touching an object that is flat, a perception that is confirmed by the rest of his fingers touching the same surface. In exploring the wall through his teacher, shared attention to the wall is obtained. They are now in co-referential attention towards the wall. At the same time as his left hand is in contact with the wall, the boy draws his right hand towards himself, moving into a 'thinking position' which is when the boy is not in direct communication or in touch with his partner (Nafstad, 2016, personal communication). For 4.9 seconds, his hand is open, fingers pointing upwards, and the form of the hand resembles a " 5 " handshape (see appendix 1 for the different handshapes). The " 5 " handshape made by his right hand, seen in connection with his left hand resting outstretched on the wall, takes the same form. It is as though he is commenting to himself that what he is sensing with his left hand has the same form as that made by him with his right hand (i.e. flat hand against object - flat hand in 'thinking position').

As he stands in his 'thinking position', he turns the " 5 " handshape, held by the right hand, into an " $\mathrm{A}$ " handshape that is held for a brief moment before he opens the hand, touches the wall and then makes a "grab around the thumb" handshape (picture 1). These changes in handshapes occur while his left thumb rests inside a physical crack in the wall, indicating that on the flat surface there is a characteristic which he stops to explore further.

Closing his right hand into an " $\mathrm{A}$ " handshape appears to indicate that there is something to grab, and he further develops the handshape by modifying it into a "grab around the thumb" handshape (picture 1), showing the characteristic of the wall that is interesting to him: the crack. The left thumb is inside the crack, the right hand taking the "grab around the thumb" handshape, making his right thumb the crack or his image of the crack, holding on to this image in the maintained handshape. It is significant that he holds this handshape for 13.9 seconds and might indicate cognitive processing of what has been, and what is now being, explored.

Picture 1: Cognitive processing of the wall's characteristics

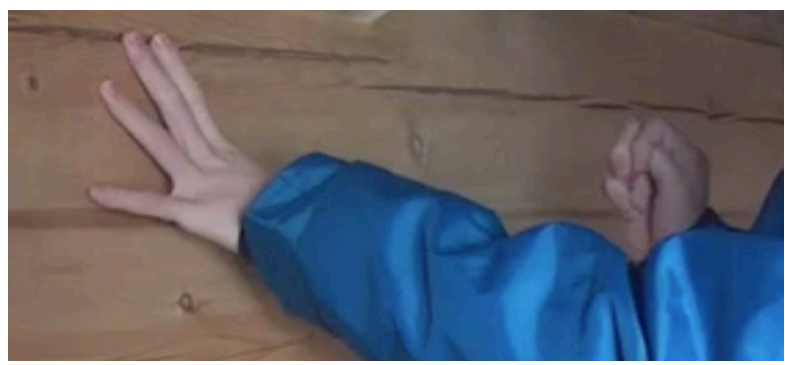


Returning to the exploration, the boy again has shared attention with his teacher towards the wall, his hand directly in contact with her hand and at the same time remaining in contact with the wall, knowing that they are both still exploring the same object. When the teacher places his left hand onto the wall, he briefly feels one of the panels before he places his left thumb inside the crack between the panel boards, holding the thumb there for 12 seconds. In this position, his hand is touched by the teacher's hand, establishing shared focus of what he is touching (i.e. the crack in the wall). During this phase, he is exploring one of the main characteristics of the wall: the cracks between the panels.

When the teacher takes his left hand and moves it down the wall, he can feel that there are several cracks in the wall, and not only the one into which he had placed his thumb. Now he places his thumb inside a new crack, further down. This gives him an overview of the wall and its characteristics; there are horizontal panels with cracks in-between them. His tactile overview of the wall is further strengthened when he aligns his attention to it through exploring through his teacher, who makes a big sweeping motion down over several panels and cracks.

Withdrawing from active exploration of the wall, the boy withdraws both hands. His right hand takes the handshape "grab around the thumb" (picture 2), which is held for 3.9 seconds, suggesting what might be cognitive processing of what has been explored is taking place. His left hand is first made into an "A" handshape and held for 2.3 seconds before he modifies it into the "grab around the thumb" handshape, which is held for 1.6 seconds. Here he uses the right hand as an anchor, processing the crack he felt, and then confirms the thought of the crack with his left hand.

Picture 2: Cognitive processing - both hands.

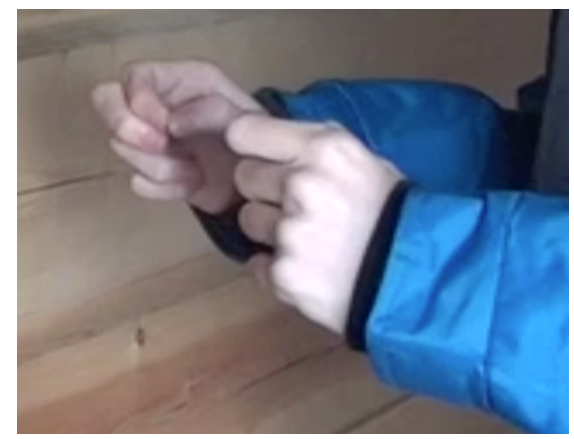

The teacher then quickly refers to the object by stroking the wall with her own hand, asking him what he felt. She gives him the position of speaker and waits for his answer. He makes a handshape and moves it back and forth; the handshape is not seen or understood by the teacher, who again asks what he was exploring. Continuously, he holds the same handshape and makes the same movements, but the teacher still does not see this handshape as an answer. 
The sign that the boy is constructing (i.e. "WALL" sign construction based on HTP) with his right hand is a " 5 " handshape, located in front of him with a movement from left to right (picture 3A and B). In addition, he holds on to the sign, suggesting mental persistence in holding onto the representation.

Reading his sign, one can see the clear iconic representation of the panel wall: the fingers are spread into the " 5 " handshape, representing the panel boards with cracks in-between them; the thumb is bent in towards the palm, showing how his thumb rested inside the crack during the exploration; and the movement from left to right shows that the panel boards were horizontal, not vertical.

Picture 3A and B: "WALL" sign construction based on HTP.
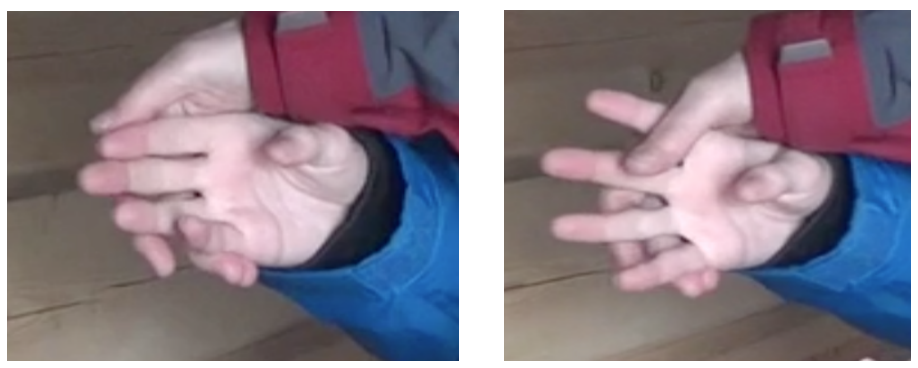

The sign construction is not understood and answered by his teacher. Instead, she leads his right hand back to the wall, aligning his attention with hers towards the wall. His hands rest on top of hers, re-exploring it, thus again establishing shared attention to the wall and its characteristics.

Again, she asks him "What was it?" The boy now signs 'WALL' conventional, using the tactile adapted sign from Norwegian Sign Language. The adapted sign is made of two "B" handshapes, palms facing each other and are touching each other in the movement of the sign (picture $4 \mathrm{~A}$ and B). Immediately the teacher understands his sign and confirms by repeating the sign in the tactile modality, saying "Wall, yes it was a wall".

Picture $4 A$ and B: 'WALL' conventional sign.
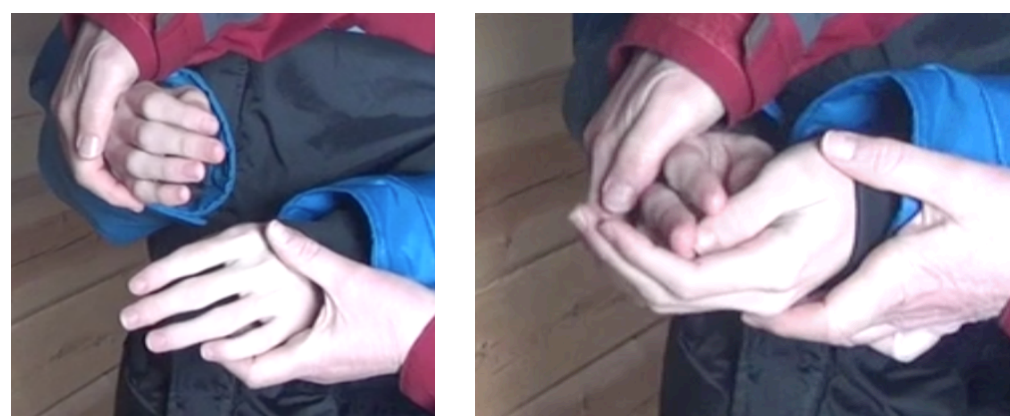
In tactually reading his teacher's sign, the boy makes a new sign variation based on how in the tactile modality he has perceived his teacher's production of the sign (i.e. the handshape and motion experienced when reading the sign is the same handshape and motion used when producing the sign). The new sign variation consists of an " $\mathrm{A}$ " handshape, as if he is closing his hand over the teacher's hand, which is then moved in a downward motion, in the same fashion in which he felt the teacher perform the sign (picture 5). These variations of signs have been labeled "signs produced as they have been perceived tactually".

Picture 5: 'WALL' as perceived from his teacher's sign.

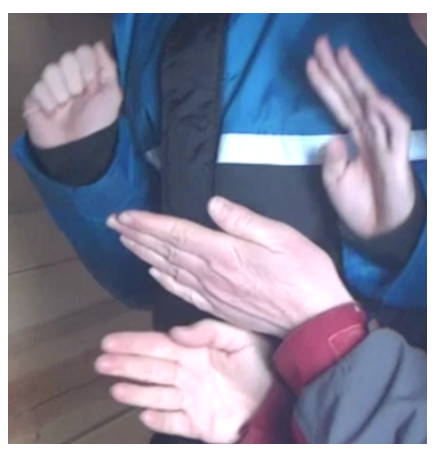

The teacher confirms the sign and the boy's hands go up to his face followed by vocalization, which is interpreted as one of his expressions of joy.

In summary, when looking at the results from the sequential analysis a salient link can be seen between tactile communication, exploration, cognitive processing and sign construction. The denominators build upon one another in a logical pattern and increasing complexity of expression is developed in doing so.

\section{Results analysis of the 'THE PACIFIER}

With the pacifier out of his mouth, making the "Pacifier in hands" sign construction handshape and moving it towards the "mouth place" (picture 6), the child seems to be referring to an object which he can hold on to and place in his mouth (i.e. the pacifier). The sign construction is of high intensity and has been interpreted as directly addressed to his father as a request for the pacifier.

Picture 6: "Pacifier in hands" sign construction held at "Mouth place".

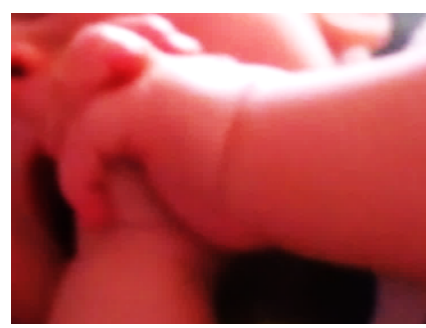


When the father touches his left underarm with the pacifier, shared attention is achieved. This is shown by the child's movement: turning his body and directing his own attention towards the object that touched him. As he already knows the pacifier intimately, it is likely that he recognizes the object as the pacifier, the object he was referring to and thinking about using the "Pacifier in hands" sign construction handshape with movement. With his attention directed towards the pacifier, the child dissolves the "Pacifier in hands" sign construction handshape which indicates that when he gets the pacifier, he no longer needs to hold on to the sign. Instead, he can further explore the pacifier orally, finding out more of the characteristics connected to the object.

Immediately after the pacifier is inserted into his mouth, the child makes the "Grasping pacifier" sign construction (picture 7 A, B, C and D) with his right hand and he holds the sign. In doing so he also holds on to the thought of what the sign represents (i.e. the object which is possible to grab with the hand that is the pacifier). The intensity of the sign construction is less and is interpreted as self-directed and showing cognitive processing.

Picture 7A, B, C and D: "Grasping pacifier" sign construction.
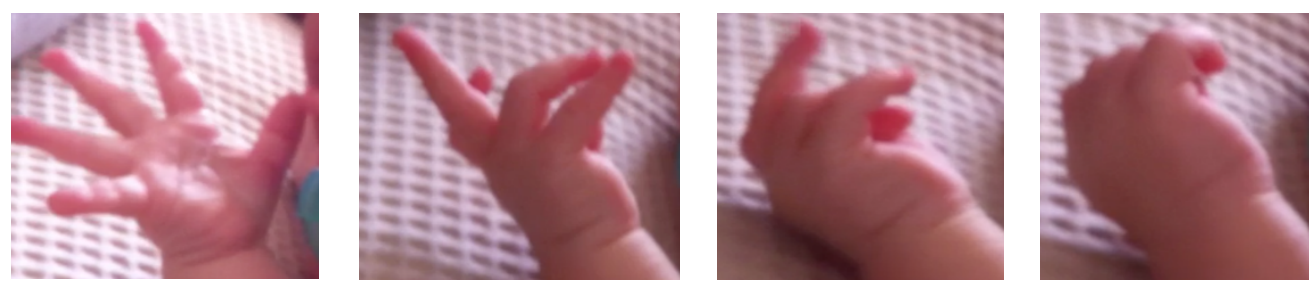

Having the pacifier in his mouth, the child refers to it by making a referential pointing-touch gesture onto and close to it showing that he is cognitively processing by referring to the thought of the pacifier. His father then removes the pacifier, and this leads to shared attention. When removed, the child experiences oral sensation getting the feel of the pacifier slipping out of his mouth.

Once the pacifier is out of his mouth, the child makes a "Grasping pacifier" sign construction pointing, indicating the pacifier that went in a certain direction, away from him. Immediately after this he makes the "Pacifier in mouth" sign construction and moves it towards the "Mouth place" (picture 8) signaling to his father to give him back the object. The same intensity is seen here as in the "Pacifier in hands" sign construction handshape and has been interpreted as directly addressed. When the father touches his arm with the pacifier, the "Pacifier in mouth" sign construction is dissolved, showing the child's awareness and attention to the pacifier, knowing that it is in reach. 
Picture 8: "Pacifier in mouth" sign construction.

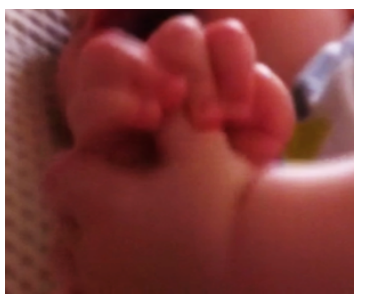

Again, the pacifier is inserted into his mouth and he can orally explore it.

The referential pointing-touch reappears, and the child uses his right hand to refer to the pacifier and his left hand as an anchor, referring to the pacifier in his mouth. He thus confirms the thought of the pacifier with his right hand, directly pointing to the pacifier. The child now makes a sign construction, a combination of "Pacifier in mouth" sign construction and "Grasping pacifier" sign construction (picture $9 \mathrm{~A}$ and B), which he places onto the pacifier which he removes from his mouth. In doing so, he is showing his cognition about the object; the object he can grab with his hand that fits in his mouth and can be taken out of his mouth. Exact elements of earlier signs and modes of use are in play in this new representation. Again, having the pacifier in his mouth, the sign's intensity is lower and is interpreted as selfaddressed, showing that the use of the sign constructions reveals the cognitive process.

Picture 9 A and B: "Pacifier in mouth" sign construction and "Grasping pacifier" sign construction.
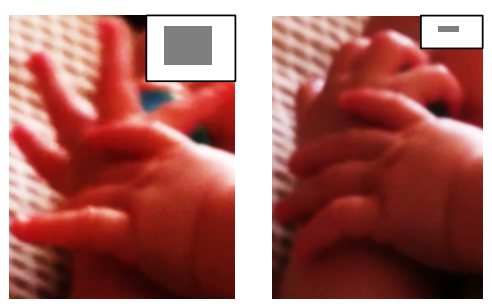

In the sequence, three common features can be seen: exploration, cognitive processing and sign construction. When looking at the whole context of the sequence, we can see that the exploration of the pacifier's salient features as explored orally, through being felt on the arm and in the form of direct touch with the object, leads to the child engaging in cognitive processing and thereafter sign construction.

Further we can see the evolving manner in which the complexity of the sign construction is built up, moving from single yet complex, structures (e.g. "Pacifier in mouth" sign construction) to combined structures with higher complexity (e.g. "Pacifier in mouth" sign construction + "Grasping pacifier" sign construction). This also suggests the evolving complexity of the child's cognitive processing, which can be said to be the basis for sign construction: Cognitive processing = sign construction; more complex cognitive processing = more complex sign construction. 


\section{Discussion}

To better understand the "first language" (i.e. the language coming from a bodily-tactile modality and from interaction with the world) of persons with CDB, looking at the linguistic elements helps us establish the origin of sign constructions (e.g. exploration and cognitive processing leading to sign constructions). Also, this perspective reveals the creative cognitive processes that take place: "when I explore, I, at the same time, think of what I am exploring. Then an image of a sign is formed in my thoughts, which I can reproduce with my hands", (interview with boy, 2016). The sign construction is therefore a non-cultivated or raw expression of the creative cognitive process that goes into the making of the sign. Persons with $\mathrm{CDB}$ tend to have a limited vocabulary from a cultural linguistic point of view (cf. e.g. Nafstad \& Rødbroe 2015). Even so, they can be very active as the present study shows, in constructing signs. The sign constructing activity, arising from the manner in which they cognize their bodily-tactile impressions from interaction with the world, must be seen as an expression of strong language-making agency in persons with CDB.

\section{Conclusion}

This study has added a linguistic perspective to the observed creativity in sign constructions made by persons with CDB. The constructions themselves being a part of their "first language" coming into fruition through the process of exploration and cognitive processing leading to sign constructions of what has been explored both physically through the hands, but also explored mentally in the cognitive process taking place.

In the research performed in this study, the author has shown that, based on exploration of the form and function of objects, persons with CDB develop sign constructions. The cognitive processing that takes place plays an important part in constructing both a mental image of what has been explored and an image of how this can be transferred into a sign construction. The linguistic elements seen in the construction show that it is possible to separate these expressions from gestures. Thus, possibilities for research are expanded, making it possible to look linguistically into the "first language" construction of persons with CDB. This can contribute to changing the status of the expressions from being seen only as idiosyncratic constructs, to idiosyncratic constructs with inherent linguistic elements. This shift in perspective can make it attractive for researchers in the field of sign language linguistics to take a new interest in mapping out the "first language" and locating it within the linguistic field. By adding a sign language perspective, as in this study, it becomes easier to treat the co-created expressions as language. This again gives room for a "second language 
acquisition" (i.e. the cultural language in the specific society) where the partners can map fluent use of conventional signs onto the "first language" utterances of the person with CDB. In this manner, the prerequisites for language acquisition would be brought closer to that of a sighted and/or hearing person.

\section{References}

Ask Larsen, F. (2003). The washing-smooth hole-fish. Dissertation. Aarhus: University of Aarhus.

Ask Larsen, F. (2016). Lecture given at the University of Groningen, Master of Science, Communication and Deafblindness, March $8^{\text {th }} 2016$.

Ask Larsen, F. (2016) Congenital deafblindness and bodily-tactile language acquisition. Dissertation. Frederiksberg: University of Copenhagen.

Bellugi, U. \& Klima, E. S. (2001). Sign Language. International Encyclopedia of the Social and Behavioral Sciences, 21, 14066-71.

Borchgrevink, H.M. (2002). Cross-modal association and cerebral plasticity -implications for assessment of the deaf-blind. Presentation at International Conference on Sensation, Perception and Construction of Meaning in Congenital Deafblindness, Gothenburg August 28-September 1 2002. Dronninglund: Nordic Staff Training Centre for Deafblind Services. Bryman, A. (2012). Social research methods. Oxford university press.

Corbin, J. \& Strauss, A. (2015). Basics of qualitative research: Techniques and procedures for developing grounded theory. Sage Publications, Inc.

Cormier, K., Quinto-Pozos, D., Sevcikoca, Z. \& Schembri, A. (2012). Lexicalisation and de-lexicalisation processes in sign languages: Comparing depicting constructions and viewpoint gestures. Language and Communication, 32, 329-348.

Daelman, M., Janssen, M., Ask Larsen, F., Nafstad, A., Rødbroe, I., Souriau, J. \& Visser, T. (2004). Congenitally deafblind persons and the emergence of social and communicative interaction. Communication Network Update Series, Number 2, 3-7.

Dammeyer, J. H., Nielsen, A., Strøm, E., Hendar, N. O. E., \& Eiriksdottir, V. K. (2015). A Case Study of Tactile Language and its Possible Structure. Journal of Communication Disorder, Deaf Studies and Hearing Aids, 3(2), pp. 1-7.

Erlenkamp, Sonja. (2009). "Gesture verb". Cognitive-visual mechanism of "classifier verbs" in Norwegian Sign Language. CogniTextes. Revue de l'Association de linguistique cognitive, 2009:3, 1-32.

Fauconnier, G. (1997). Mappings in thought and language. Cambridge, UK: Cambridge University Press.

Fauconnier, G. \& Turner, M. (2002). The way we think: conceptual blending and the mind's hidden complexities. New York: Basic Books.

Flyvbjerg, B. (2004). Phronetic planning research: Theoretical and methodological reflections. Planning Theory \& Practice, 5(3), 283-306. 
Gallagher, S. \& Zahavi, D. (2008). The Phenomenological Mind. An Introduction to Philosophy of Mind and Cognitive Science. New York: Routledge.

Hamm, B., \& Mirenda, P. (2006). Post-school quality of life for individuals with developmental disabilities who use AAC. Augmentative and Alternative Communication, 22(2), 134-147.

Heidegger, M. (1986). Sein und Zeit. Tübingen: Max Niemeyer. Being and Time. Trans. J. Stambaugh. Albany: SUNY, 1996.

Hoffmann, J. N., Montag, A. G., \& Dominy, N. J. (2004). Meissner corpuscles and somatosensory acuity: the prehensile appendages of primates and elephants. The Anatomical Record Part A: Discoveries in Molecular, Cellular, and Evolutionary Biology, 281(1), 1138-1147.

Janssen, M. J., Riksen-Walraven, J. M., \& van Dijk, J. P. (2006). Applying the diagnostic intervention model for fostering harmonious interactions between deaf-blind children and their educators: A case study. Journal of Visual Impairment \& Blindness, 100(2), 91105.

Johnson, M. (1987). The body in the mind: The bodily basis of meaning, imagination, and reason. University of Chicago Press.

Liddell, S. K. (2000). Blended spaces and Deixis. In D. McNeill (Ed.), Language and gesture, Cambridge, UK: Cambridge University Press.

Liddell, S. K. (2003). Grammar, Gesture, and Meaning in American Sign Language. Cambridge University Press.

Linell, P. (2009). Rethinking language, mind, and world dialogically. Charlotte, NC: Information Age Publishing, INC.

Markova, I. (2003). Validation and generalization using single-case studies: A dialogical approach. Research paper.

McDonald, B.H., 1983. Productive and frozen lexicon in ASL: An old problem revisited. In W.C. Stokoe and V. Volterra,V. (eds.), SLR' 83 Proceedings of the Third International Symposium on Sign Language Research. Rome, Silver Spring: Linstok Press.

Nafstad, A. \& Rødbroe, I. (2015). Communicative Relations: Interventions that create communication with persons with congenital deafblindness. Aalborg: Materialecenteret.

Nafstad, A. \& Vonen, A. M. (2000). Des gestes tactiles aux symbols: une perspective transactionelle dans la négociation du sens. Enfance. Revue trimestrielle, Vol. 52, pp. 4965.

Nelson, K. (1996). Language in cognitive development: The emergence of the mediate mind. Cambridge University Press.

Nicholas, J. (2004). Communicating Research to Practice and Practice to Research: From theoretical contributions to therapeutic interventions. NUD Publication No.43. Dronninglund: Nordic Staff Training Centre for Deafblind Services.

Nicholas, J. (2010). From active touch to tactile communication - what's tactile cognition got to do with it? Aalborg: The Danish Resource Centre on Congenital Deafblindness.

Radden, G. \& Kövecses, Z. (1999). Towards a theory of metonymy. In K.-U. Panther, and G. Radden (Eds.), Metonymy in Language and Thought. Amsterdam: John Benjamins.

Sameroff, A. J., \& Fiese, B. H. (2000). Transactional regulation: The developmental ecology of early intervention. Handbook of early childhood intervention, 2, 135-159. 
Souriau, J. Rødbroe, I. \& Janssen, M. (2008). Communication and Congenital Deafblindness. III: Meaning making. Aalborg: Materialecenteret.

Souriau, J. (2015). Blended Spaces and Deixis in Communicative Activities Involving Persons with Congenital Deafblindness. Journal of Deafblind Studies on Communication, 1(1), 5-22.

Stokoe, W. C. Jr. (2005). Sign Language Structure: An Outline of the Visual Communication Systems of the American Deaf. Journal of Deaf Studies and Deaf Education, 10, 3-37.

Supalla, T. 1982. Structure and acquisition of verbs of motion and location in ASL. Unpublished dissertation. San Diego: University of California,.

Taub, Sarah F. (2001). Language from the body. Iconicity and Metaphor in American Sign Language. Cambridge University Press

Wilcox, S., Perrin Wilcox, P., \& Jarque, M. J. (2003). Mappings in conceptual space: Metonymy, metaphor, and iconicity in two signed languages. Jezikoslovlje, 4(1), 139-156.

Goran Andreas Gregor Caspian Forsgren, MSc., Senior Advisor, Department of Dual Visual and Hearing Loss and Deafblindness, Statped, Norway;; e-mail: < Goran.Forsgren@statped.no>.

Marlene Daelman, Educational Psychologist, MFC De KadeSpermalie, Belgium; Lecturer, Department of Special Needs Education and Youth Care, University of Groningen; e-mail: <marlene.daelman@skynet.be>.

Paul Hart, Head of Research and Practice, Sense Scotland, Touchbase, Glasgow, United Kingdom; e-mail: <phart@sensescotland.org>. 
Table of handshapes commonly used in Norwegian Sign Language.

\begin{tabular}{|l|l|l|l|l|l|}
\hline «A» hand & «B» hand & Horizontal & Vertical «B» & Pointing hand & Pointing \\
\hline hand used
\end{tabular}

